\title{
Lessons Learned from Compounding Tragedies
}

\author{
Eric S Kastango
}

Ceveral months have passed since news broke of a horrific $\checkmark$ compounding tragedy at the New England Compounding Center (NECC) in Framingham, Massachusetts. An outbreak of fungal meningitis in fall 2012 was traced to contaminated methylprednisolone acetate prepared by the NECC. According to the US Centers for Disease Control and Prevention (CDC), ${ }^{1}$ as of May 11, 2013, 55 deaths and a total case count of 741 had been attributed to the contamination, and the numbers continue to rise. Patients who received medications from this pharmacy have also experienced paraspinal, spinal, and peripheral joint infections.

The Institute for Safe Medication Practices (ISMP) has compiled a list of selected compounding misadventures since the 1990s. ${ }^{2}$ For legal reasons, many compounding misadventures never become public, but the US Food and Drug Administration (FDA) has been actively inspecting compounding pharmacies with a history or suspicion of large-scale compounding or quality concerns.,

Compounding problems are not isolated to the United States. Recently, more than 1200 cancer patients in Ontario and New Brunswick received chemotherapy solutions with concentrations below labelled specifications. It appears that jurisdictional issues regarding proper oversight of this operation and others were similar to the problems identified in relation to the NECC event. ${ }^{5,6}$

It is time to face our naïveté and our occasional arrogance about safe compounding practices. We must learn from these events and take measures to ensure that we are doing everything possible to protect patients and reduce the risk of improperly compounded sterile preparations. On a personal level, I have been profoundly affected by the NECC event, and I continue to be perplexed by the actions of some of my colleagues who somehow still believe that the principles of contamination control and robust quality systems don't apply to them. As a pharmacist and a potential future patient, I ask, "What are you doing for your present-day and future patients in light of these recent issues?"

Whether you agree or disagree with United States Pharmacopeia (USP) Chapter <797> and other USP chapters critical to compounding ${ }^{7}$ or the Pharmaceutical Inspection
Cooperation Scheme's compounding guide, ${ }^{8}$ the message couldn't be clearer. Business as usual is no longer acceptable. We must embrace standards and guidelines that incorporate evidencebased science and best practices that have been vetted through public comment and review cycles.

More specifically, it is

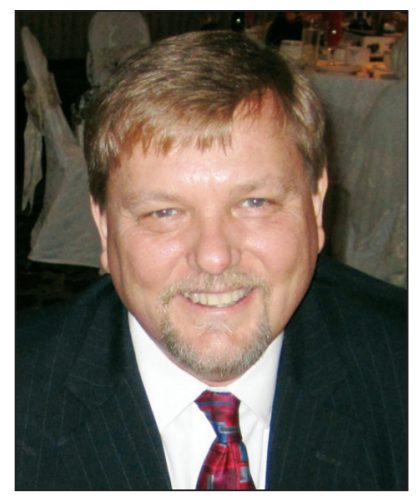
time to perform risk assessments of the compounding methods used in our own pharmacies, so that inherent risks can be identified and mitigated through detailed policies and procedures, robust training programs and quality systems. Pharmacy staff members must know not only what is expected of them as they prepare sterile dosage forms, but also why they are expected to do these things. We must move away from the pure apprenticeship model of training and instead deploy methods and procedures that establish a solid foundation for quality work practices that will prevent compounding errors.

Pharmacy practitioners are increasingly challenged to prepare compounded sterile dosage forms that are not commercially available, at times using nonsterile active pharmaceutical ingredients. Handling and transforming these components into appropriate sterile dosage forms may require greater experience and expertise than a particular pharmacy possesses. In such cases, we must take these limitations into account and recognize the risks they pose to our patients. In particular, only robust and validated procedures should be used. We have the responsibility to ensure that any compounded preparation is what it is expected to be and, to the degree possible, to ensure and measure its sterility. Conversely, if we don't have the requisite expertise, we should not undertake these activities.

Historically, pharmacists compounded medications in a "just in time" manner. However, current distribution models require that more compounded sterile preparations be stored at room temperature, prompting the desire for longer beyond-use dating. The sterility tests described in USP Chapter $<71>$ 
are industrial-grade tests designed to detect events of gross contamination, but they are difficult to perform when small batches of medications are prepared for which the desired beyond-use dates exceed the limits detailed in USP Chapter $<797>$. As such, passing a USP Chapter $<71>$ test is a lagging indicator of quality. We need to focus on building quality into all compounded sterile preparations through the development of robust, proven processes yielding medications of expected quality (in terms of both drug strength and sterility).

As Julius Caesar's armies crossed the Rubicon in 49 BC, he said "alea iacta est" — "The die is cast." Pharmacy has crossed its own Rubicon. The FDA's inspections of US compounding pharmacies have been aggressive, and I applaud the actions taken to assess the magnitude of certain large "untraditional pharmacies". Several US state boards of pharmacy are now performing inspections or using other methods to assess operational compliance with USP Chapter <797> among community and hospital pharmacies (regardless of whether current state regulations require such compliance). Some states have enhanced their sterile compounding regulations, whereas dozens of others are mobilizing to address deficiencies in their laws. The National Association of Boards of Pharmacy has partnered with compounding specialists to offer training assistance in sterile compounding to state board of pharmacy inspectors. The CDC supports USP Chapter <797> and has published guidance for safe injection practices to prevent transmission of infections to patients. ${ }^{9}$ The Canadian Society of Hospital Pharmacists (CSHP) guidelines on sterile compounding $^{10}$ are currently undergoing revision and will most likely take into account what is being learned from these events and others.

The science behind the requirements in USP Chapter $<797>$ and the CSHP guidelines on sterile compounding is not new. When the American Society of Hospital Pharmacists (now the American Society of Health-System Pharmacists) published its guidelines in 1993, Kenneth E Avis, considered by many as the father of good compounding practices in pharmacy, was quoted as saying, "This is not new science, but rather old news that few bothered to heed." As the ISMP has said, "Unfortunately, there are too many in healthcare who feel that, if it hasn't happened to them, the adverse experiences of others do not apply." 2 Let's honour those harmed by doing the right things now.

\section{References}

1. Multi-state meningitis outbreak-current case count. Persons with fungal infections linked to steroid injections, by state [map]. Atlanta (GA): Centers for Disease Control and Prevention; 2013 May 6 [cited 2013 May 11]. Available from: www.cdc.gov/hai/outbreaks/meningitis-map-large.html

2. Sterile compounding tragedy is a symptom of a broken system on many levels. ISMP Med Saf Alert 2012 Oct 18 [cited 2013 May 11]. Available from: www.ismp.org/Newsletters/acutecare/showarticle.asp?id=34

3. 2013 pharmacy inspections. Silver Spring (MD): US Department of Health and Human Services, Food and Drug Administration; 2013 [cited 2013 Apr 11]. Available from: www.fda.gov/AboutFDA/CentersOffices/Officeof
GlobalRegulatoryOperationsandPolicy/ORA/ORAElectronic ReadingRoom/ucm 340853.htm

4. [Inspection report]. Silver Spring (MD): US Department of Health and Human Services, Food and Drug Administration; 2012 [cited 2013 Apr 11]. Available from: www.fda.gov/downloads/AboutFDA/CentersOffices/ OfficeofGlobalRegulatoryOperationsandPolicy/ORA/ORAElectronic ReadingRoom/UCM325980.pdf

5. Zafar A. Chemotherapy outsourcing done by hospitals across Canada. CBC News, Health; 2013 Apr 25 [cited 2013 May 11]. Available from: www.cbc.ca/news/health/story/2013/04/24/chemotherapy-baxter.html

6. Chemo scandal: Health Canada cracks down on private drug suppliers. TheSpec.com; 2013 Apr 20 [cited 2013 May 11]. Available from: www. thespec.com/news/local/article/922024--chemo-scandal-health-canadacracks-down-on-private-drug-suppliers

7. USP [United States Pharmacopeia] 36-NF [National Formulary] 36. Rockville (MD): US Pharmacopeial Convention; 2012.

8. PIC/S guide to good practices for the preparation of medicinal products in healthcare establishments. PE 010-3. Geneva (Switzerland): Pharmaceutical Inspection Convention Secretariat and Pharmaceutical Inspection CoOperation Scheme (PIC/S); 2008 Oct 1 [cited 2013 May 14]. Available from: www.picscheme.org/pdf/23_pe0103-revisedgppguide.pdf

9. Protect patients against preventable harm from improper use of single-dose/single-use vials. Atlanta (GA): Centers for Disease Control and Prevention, National Center for Emerging and Zoonotic Infectious Diseases, Division of Healthcare Quality Promotion; 2012 May 2 [cited 2013 Apr 11]. Available from: www.cdc.gov/injectionsafety/CDCposition-SingleUse Vial.html

10. Sterile preparation of medicines: guidelines for pharmacies. Ottawa $(\mathrm{ON})$ : Canadian Society of Hospital Pharmacists; 1996. Under review.

Eric S Kastango, MBA, RPh, FASHP, is President and CEO of ClinicallQ, LLC, and CriticalPoint, LLC, in Florham Park, New Jersey.

Competing interests: Eric Kastango is a faculty member for the Sterile Compounding Boot Camp presented by CriticalPoint, LLC. He has provided expert testimony, on topics outside the subject of this editorial, for the Virginia Board of Pharmacy and has received speaker's fees and payment for travel and meeting expenses from numerous professional pharmacy organizations. He has also received royalties from Pharmacy OneSource (Wolters Kluwer Health). The views, perceptions, comments, thoughts, and written or otherwise stated positions are strictly those of the author and shall not be interpreted as official position by any applicable organizations or individuals, living or dead.

\section{Address correspondence to:}

Eric S Kastango

Clinical IQ, LLC

235 Main Street, Suite 292

Madison NJ 07940 USA

e-mail: eric.kastango@clinicaliq.com

This guest editorial is one of a continuing series in which prominent pharmacists are asked to comment on current issues facing the profession. In selecting an editorialist to discuss issues and concerns related to the compounding of medications, the Editorial Board sought the perspectives of a pharmacist working outside of Canada, in part to emphasize that such problems are not limited by geographic boundaries. 